\title{
Persistent recurring wheezing in the fifth year of life after laboratory-confirmed, medically attended respiratory syncytial virus infection in infancy
}

\author{
Gabriel J Escobar ${ }^{1 *}$, Anthony S Masaquel ${ }^{2}$, Sherian X Li ${ }^{1}$, Eileen M Walsh ${ }^{1 *}$ and Patricia Kipnis ${ }^{3}$
}

\begin{abstract}
Background: Respiratory syncytial virus (RSV) infection in infancy is associated with subsequent recurrent wheezing. Methods: A retrospective cohort study examined children born at $\geq 32$ weeks gestation between 1996-2004. All children were enrolled in an integrated health care delivery system in Northern California and were followed through the fifth year of life. The primary endpoint was recurrent wheezing in the fifth year of life and its association with laboratory-confirmed, medically-attended RSV infection during the first year, prematurity, and supplemental oxygen during birth hospitalization. Other outcomes measured were recurrent wheezing quantified through outpatient visits, inpatient hospital stays, and asthma prescriptions.

Results: The study sample included 72,602 children. The rate of recurrent wheezing in the second year was 5.6\% and fell to $4.7 \%$ by the fifth year. Recurrent wheezing rates varied by risk status: the rate was $12.5 \%$ among infants with RSV hospitalization, $8 \%$ among infants 32-33 weeks gestation, and 18\% in infants with bronchopulmonary dysplasia. In multivariate analyses, increasing severity of respiratory syncytial virus infection was significantly associated with recurrent wheezing in year 5; compared with children without RSV infection in infancy, children who only had an outpatient RSV encounter had an adjusted odds ratio of 1.38 (95\% Cl,1.03-1.85), while children with a prolonged RSV hospitalization had an adjusted odds ratio of $2.59(95 \% \mathrm{Cl}, 1.49-4.50)$.
\end{abstract}

Conclusions: Laboratory-confirmed, medically attended RSV infection, prematurity, and neonatal exposure to supplemental oxygen have independent associations with development of recurrent wheezing in the fifth year of life.

Keywords: Respiratory syncytial virus, Recurrent wheezing, Prematurity

\section{Background}

Respiratory syncytial virus (RSV) infection is common during childhood; attack rates approach $100 \%$ by age 3 years [1]. Most infants have mild upper respiratory infections, but a significant proportion develop more severe lower respiratory tract disease [1]. The most important of these infections is bronchiolitis, and RSV is responsible for 50 to $80 \%$ of bronchiolitis hospitalizations and is the leading cause of hospitalization in children younger than 1 year in the United States [2-4].

\footnotetext{
* Correspondence: gabriel.escobar@kp.org; eileen.m.walsh@kp.org 'Division of Research, Perinatal Research Unit, Kaiser Permanente Medical Care Program, Oakland, CA, USA

Full list of author information is available at the end of the article
}

A number of studies have reported an association between RSV infection and subsequent recurrent wheezing and early childhood asthma [5-12]. In particular, two recent reports have explored this relationship using large cohorts. Carroll et al. described the association between full-term children who had outpatient visits or hospitalizations for bronchiolitis in infancy and asthma in the sixth year of life [13]. They demonstrated the presence of a severity gradient (increased severity of bronchiolitis correlated with increased asthma severity). Using a more rigorous, laboratory-confirmed definition for RSV infection, our team previously reported a similar relationship between RSV infection and recurrent wheezing in the

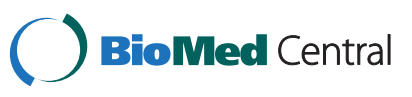


third year of life among both premature and full-term infants [14].

In this report, we describe the outcomes of a cohort of children born at $\geq 32$ weeks gestational age (GA) who were followed through the fifth year of life. Because the association between RSV infection and asthma has been reported to decrease as the age of follow-up increases $[5,6,15,16]$, we wanted to address this issue with an expanded cohort with two additional years of follow-up. Our goal was to quantify the relationship between laboratory-confirmed, medically attended RSV infection in the first year of life with the presence of recurrent wheezing (RW) during a time period when the prevalence of these conditions is expected to decrease [17]. We also explored the degree to which the relationships we found were dependent on the RW definition.

\section{Methods}

\section{Study design}

We collected data from Kaiser Permanente Northern California (KPNC), an integrated health care delivery system. This study was approved by the KPNC Institutional Review Board, which has jurisdiction over all the hospitals and clinics involved in this study. The inception cohort, described in detail in our previous report [14], included infants meeting the following criteria: birth at the KPNC Oakland, Hayward, Sacramento, San Francisco, Santa Clara, or Walnut Creek hospitals; date of birth from 1/1/96 through 12/31/04 (this study added infants born between 1/1/03 through 12/31/04; our previous cohort included births through 12/31/02); $\geq 32$ weeks GA at birth; infant survived the birth hospitalization; and use of or membership in Kaiser Foundation Health Plan, Inc. during the first year of life.

\section{Study outcomes}

Our primary study outcome was the occurrence of RW in the fifth year of life (fourth birthday through the day before the fifth birthday; henceforth, RW5). We defined $\mathrm{RW}$ as in our previous report using a combination of encounter events, patient diagnoses, and prescription patterns [14]. Using this definition, we determined whether children in our cohort met this definition in years $2,3,4$, and 5 as well as examining the prevalence of any RW across years 2 through 5 . We also tested a lenient definition termed "tentative asthma diagnosis" (TAD) in which we accepted any instance of International Classification of Diseases (ICD9) [18] diagnosis code for asthma (493.xx) in a given year at face value (i.e., we did not have strict criteria for number of encounters, nor did we use prescription data). Children categorized with TAD during years 2 through 5 were sorted into 4 hierarchical, mutually exclusive categories based on the year of life in which they were diagnosed.

\section{Predictors}

The primary study predictor was the occurrence of laboratory-confirmed, medically attended RSV infection in the first year of life (henceforth, "RSV infection"). We also examined whether infants were infected with adenovirus, parainfluenza virus, influenza A or B virus, or Bordetella pertussis. We considered outpatient visits, emergency department (ED) visits, and inpatient hospitalization with diagnosis codes for each type of pathogen to be medically attended events. A medically attended event was considered to be laboratory-confirmed if there was a positive test for the pathogen within \pm 14 days of the encounter. Pathogens were identified using direct fluorescent antibody testing or culture. We categorized medically attended encounters for RSV and other pathogens as outpatient (including scheduled clinic visits, unscheduled urgent care visits, and ED visits), uncomplicated hospitalizations (hospitalizations with a total length of stay [LOS] $<96$ hours without assisted ventilation), or prolonged hospitalizations (hospitalizations lasting $\geq 96$ hours or in which assisted ventilation occurred). Race was included as a predictor and assessed in this study because of the well-known differences in RSV infection severity by race. The other predictors - infant sex, maternal age, birth weight, GA, small for GA status, oxygen exposure during the neonatal period, family history of asthma as found in physicians' Significant Problem List or because of parental visits for asthma, bronchopulmonary dysplasia, presence of congenital anomalies, number of siblings present in the home, and hospitalizations for unspecified respiratory illnesses - were defined as previously reported [14].

\section{Attrition}

To be included in our main analyses, each child in the cohort had to be a member for at least 9 months in each of the first five years of life. To make this determination, we linked the study children's utilization and membership data and created a monthly membership variable which was set equal to 1 (patient was a member during that month and/or had outpatient or inpatient use during that month) or 0 (patient was not a member during that month and did not have outpatient or inpatient use during that month) to determine eligibility for inclusion in the study cohort.

\section{Data collection}

The KPNC information systems employ a common medical record number for all inpatient, outpatient, and administrative encounters in all facilities, permitting extraction and linkage of patient data using methods that have been previously described [19-22]. Care received outside the program was also tracked. We identified infants using the KPNC hospitalization database and the Neonatal Minimum Data Set [23], a database that captures supplemental oxygen use and assisted ventilation among infants receiving neonatal 
intensive care. These records were linked to patient demographic, membership, laboratory, pharmacy, outpatient encounter, and hospitalization databases to obtain the previously described variables.

\section{Statistical analyses}

Statistical analyses were conducted using SAS (SAS Institute, Cary, NC). Unadjusted odds ratios (ORs) for all predictors were calculated using logistic regression [24] with RW5 as the outcome and each of the predictors as the only explanatory variable. Values of categorical variables were compared using a chi-square or Fisher exact test. Normally distributed continuous variables were compared using a Student $t$ test. Comparisons of non-normally distributed continuous variables employed the Wilcoxon rank sum test.

We conducted multivariate analyses in three ways. We employed both logistic regression models in which children were included based on the abovementioned membership criteria as well as Cox proportional hazards modeling [24] (to account for censoring of infants). Because the results of Cox models were similar, we report those results in Additional file 1 Table S1; logistic regression models are reported in this paper. We also performed logistic regression using RW2, RW3, RW4, and RW5 cohorts so that we could assess the change in association as the length of follow-up increased.

The relative contribution of each predictor was calculated using the differences between the log likelihood of the full model and the log likelihood of a model without each of the predictors and was defined as the ratio of its $\log$ likelihood difference to the sum of the likelihood differences from all predictors $\times 100$ [25].

\section{Results}

\section{Study participants}

Scanning KPNC databases identified 165,366 infants who survived to discharge from the birth hospitalization during 1996-2004. Infants were excluded from the study due to missing data $(n=358)$, prematurity $(<32$ weeks GA [most received RSV immunoprophylaxis]; $\mathrm{n}=2,371$ ) and not meeting membership criteria $(n=19,913)$. The final study cohort consisted of 142,724 infants $\geq 32$ weeks GA. Of these, 72,602 met membership criteria during the first 5 years of life and constitute the analysis cohort. Among these infants, 43,786 , or $60.3 \%$, were also in our original cohort. Additional details, including a cohort assembly flow chart, are available in Additional file 1 Figures S1 and S2.

Subject demographics are reported in Table 1. The study population is ethnically diverse, and the majority of mothers $(73 \%)$ were $18-34$ years of age. Using maternal records, we determined that $3.6 \%$ of infants had a maternal history of asthma.

\section{RSV infection and the prevalence of recurrent wheezing}

Using logistic regression, documented RSV infection in the first year of life was associated with an increased risk of RW5, and a severity gradient was evident (Table 2). For example, RSV infection that only involved an outpatient encounter had an adjusted odds ratio (AOR) of 1.38 (95\% CI, 1.03-1.85), whereas if it involved prolonged hospitalization the AOR was 2.59 (95\% CI, 1.49-4.50). Exposure to oxygen in the neonatal period also showed a similar gradient. In contrast, infections with other pathogens were not associated with increased rates of RW5, although prolonged hospitalizations with unspecified organisms did show a strong association (AOR, 3.46, 95\% CI, 1.94-6.16). Gestational age $<37$ weeks was also associated with increased risk of RW5 (Table 2). The relative contribution of RSV infection to the overall predictive ability of our model was $6.6 \%$, whereas the relative contribution of oxygen exposure was $4.9 \%$. In contrast, the relative contribution of non-modifiable risk factors was $22.8 \%$ for sex, $4.8 \%$ for GA, $21.2 \%$ for race, and $28.7 \%$ for family history of asthma.

The prevalence of RW by individual years and across years 2 through 5 is reported in Table 3 . Across all children, the prevalence of RW decreased over time from $5.6 \%$ in year 2 to $4.7 \%$ in year 5 . However, depending on the presence of risk factors, the rate of RW in year 2 and the rate of decline during early childhood may be substantially different. For example, $25.0 \%$ of children with laboratory-confirmed RSV hospitalization in their first year had RW in the second year of life. These infants were approximately three times as likely to have RW5 than children who did not ( $12.5 \%$ vs. $4.6 \%)$, and approximately three times as likely to ever have had RW in years $2-5$ $(40.0 \%$ vs $12.3 \%)$. Figure 1 shows that a severity gradient (increased severity of RSV infection in infancy is associated with an increased prevalence of RW) is evident across the second through fifth years of life. The association between RSV infection, RW, and prematurity is reported in Additional file 1 Figure S3, which provides additional displays of this gradient among children born at $<37$ and $\geq 37$ weeks GA. In addition, the AOR for all types of RSV infection tended to fall as the dependent variable was changed from RW2 to RW5. For example, the AORs for an outpatient RSV encounter for RW2 through RW5 were $3.18,2.21,2.11$, and 1.36. Additional results are shown in Additional file 1 Table S3.

Use of a more lenient tentative asthma diagnosis to capture RW events did not lead to any directional change in our findings, but rather a general increase in the prevalence of reported outcomes. The proportion of children with RW5 using our strict definition was $4.6 \%$, but increased to $10.3 \%$ when using the more lenient definition; however, the overall trends in the data remained consistent. Tabular data using this alternative definition is shown in 
Table 1 Description of infants born during 1996-2004 by gestational age categories

\begin{tabular}{|c|c|c|c|c|c|c|}
\hline & \multicolumn{5}{|c|}{ Gestational age, wk } & \multirow[b]{2}{*}{ All gestational age } \\
\hline & $32-33$ & $34-36$ & 37 & $38-40$ & $\geq 41$ & \\
\hline $\mathrm{N}$ & 936 & 4,665 & 4582 & 51,049 & 11,370 & 72,602 \\
\hline Male sex, $\%$ & 51.07 & 54.81 & 53.40 & 50.44 & 50.71 & 50.96 \\
\hline \multicolumn{7}{|l|}{ Race, \%* } \\
\hline White & 46.79 & 43.09 & 39.90 & 42.87 & 47.65 & 43.50 \\
\hline African-American & 11.32 & 10.40 & 9.41 & 8.57 & 9.30 & 8.89 \\
\hline Asian & 16.35 & 19.85 & 23.42 & 20.74 & 15.27 & 19.94 \\
\hline Hispanic & 16.99 & 18.93 & 20.32 & 21.25 & 20.81 & 20.92 \\
\hline Other/unknown & 8.55 & 7.74 & 6.96 & 6.56 & 6.97 & 6.75 \\
\hline \multicolumn{7}{|l|}{ Maternal age, y, \% } \\
\hline$<18$ & 2.24 & 1.29 & 1.18 & 1.19 & 1.49 & 1.25 \\
\hline $18-34$ & 67.20 & 68.75 & 70.76 & 73.58 & 74.64 & 73.17 \\
\hline$>35$ & 30.56 & 29.97 & 28.07 & 25.23 & 23.87 & 25.57 \\
\hline \multicolumn{7}{|l|}{ Family history of asthma, $\%^{\dagger}$} \\
\hline None & 93.91 & 94.23 & 94.43 & 94.82 & 95.15 & 94.80 \\
\hline Father only & 2.03 & 1.63 & 1.66 & 1.49 & 1.37 & 1.50 \\
\hline Mother only & 4.06 & 4.14 & 3.84 & 3.60 & 3.42 & 3.63 \\
\hline Both parents & 0.00 & 0.00 & 0.07 & 0.09 & 0.06 & 0.08 \\
\hline${ }^{3} 1$ sibling $<5$ y of age in home, $\%$ & 42.95 & 42.17 & 39.57 & 39.51 & 32.22 & 38.58 \\
\hline Congenital anomaly present, $\%^{\ddagger}$ & 13.14 & 10.33 & 7.77 & 6.52 & 6.24 & 6.88 \\
\hline Small for gestational age, $\%^{\S}$ & 4.59 & 3.41 & 2.23 & 1.25 & 0.67 & 1.40 \\
\hline \multicolumn{7}{|l|}{ Oxygen exposure ${ }^{\|}$and BPD, \%" } \\
\hline No oxygen, no BPD & 55.77 & 86.13 & 96.49 & 97.77 & 96.31 & 96.17 \\
\hline$<200$ hours oxygen, no BPD & 37.50 & 12.24 & 3.12 & 1.95 & 3.26 & 3.35 \\
\hline${ }^{3} 200$ hours oxygen, no BPD & 5.24 & 1.29 & 0.37 & 0.25 & 0.40 & 0.41 \\
\hline $\mathrm{BPD}$ & 1.50 & 0.34 & 0.02 & 0.03 & 0.04 & 0.07 \\
\hline Unspecified respiratory hospitalization \% ${ }^{\#}$ & 15.92 & 15.05 & 12.40 & 8.09 & 7.19 & 8.77 \\
\hline $\begin{array}{l}\text { Laboratory-confirmed, medically attended } \\
\text { RSV infection, \%** }\end{array}$ & 3.95 & 2.98 & 2.14 & 1.64 & 1.36 & 1.74 \\
\hline Admitted to hospital, $\%^{\neq \neq}$ & 2.46 & 1.31 & 0.87 & 0.63 & 0.49 & 0.69 \\
\hline Treated as outpatient, \% ${ }^{\S \S}$ & 1.50 & 1.67 & 1.27 & 1.00 & 0.87 & 1.05 \\
\hline $\begin{array}{l}\text { Laboratory-confirmed, medically attended } \\
\text { infection with other pathogen, } \%^{+\dagger}\end{array}$ & 0.64 & 0.58 & 0.31 & 0.28 & 0.25 & 0.30 \\
\hline Admitted to hospital, $\%^{\ddagger \neq}$ & 0.53 & 0.28 & 0.13 & 0.13 & 0.11 & 0.14 \\
\hline Treated as outpatient, \% ${ }^{\S \S}$ & 0.11 & 0.3 & 0.17 & 0.16 & 0.14 & 0.16 \\
\hline
\end{tabular}

Abbreviations: BPD Bronchopulmonary dysplasia, CI Confidence interval, RSV Respiratory syncytial virus, wk week, y year.

*Classification of race/ethnicity in this study was based on the race of infants' mothers, as self-reported to the birth certificate clerk interviewing them at the Kaiser Permanente hospitals described in this study. Race was assessed in this study because of the well-known differences in RSV infection severity by race.

${ }^{\dagger}$ Ascertained by electronic scanning of parental records, which included encounters and diagnoses identified in the Significant Problem List by the parent's physician.

"See text for list of included International Classification of Diseases codes.

s Based on the algorithm of Brenner WE, et al. Am J Obstet Gynecol. 1976;126:555-564.

"Oxygen exposure, in hours, during the birth hospitalization. See text for details.

"All infants with BPD had $\geq 200$ hours of oxygen exposure during the neonatal period.

${ }^{\#}$ Hospitalization for pneumonia or other respiratory illness without laboratory confirmation for RSV or the other pathogens listed in footnote ${ }^{+t}$.

** Medically attended visit where positive RSV direct fluorescent antibody test or viral culture occurred within \pm 14 days of visit.

${ }^{+\dagger}$ Medically attended encounter where a positive test result (direct fluorescent antibody test, viral culture, or bacterial culture) for adenovirus, influenza virus,

parainfluenza virus 1 or 2, or Bordetella pertussis occurred within \pm 14 days of encounter.

\#¥ The encounter included a hospital admission.

$\S \S$ The encounter included outpatient care only. 
Table 2 Risk factors for recurrent wheezing in the fifth year of life using logistic regression*

\begin{tabular}{|c|c|c|c|c|}
\hline & Beta & $\begin{array}{l}\text { Adjusted } \\
\text { odds ratio }\end{array}$ & $95 \% \mathrm{Cl}$ & $P$ Value \\
\hline \multicolumn{5}{|l|}{ Sex } \\
\hline Male & 0.40 & 1.49 & $1.39-1.60$ & $<.0001$ \\
\hline Female & reference & & & \\
\hline \multicolumn{5}{|l|}{ Race $^{\dagger}$} \\
\hline White & reference & & & \\
\hline African-American & 0.53 & 1.71 & $1.52-1.91$ & $<.0001$ \\
\hline Asian & 0.31 & 1.36 & $1.24-1.49$ & $<.0001$ \\
\hline Hispanic & 0.10 & 1.11 & $1.01-1.22$ & 0.0356 \\
\hline Other/unknown & 0.22 & 1.25 & $1.09-1.44$ & 0.00 \\
\hline \multicolumn{5}{|l|}{ Maternal age, y } \\
\hline$<18$ & -0.07 & 0.94 & $0.69-1.28$ & 0.67 \\
\hline $18-34$ & reference & & & \\
\hline$\geq 35$ & 0.04 & 1.04 & $0.96-1.13$ & 0.332 \\
\hline \multicolumn{5}{|c|}{ Family history of asthma $^{+}$} \\
\hline Unknown & reference & & & \\
\hline Father only & 0.59 & 1.81 & $1.44-2.27$ & $<.00$ \\
\hline Mother only & 0.76 & 2.15 & $1.87-2.47$ & $<.00$ \\
\hline Both parents & 0.53 & 1.70 & $0.61-4.71$ & 0.31 \\
\hline
\end{tabular}

Siblings $<5$ y of age

in house

None
$\geq 1$
Congenital anomaly
Present
Absent

Small for gestational age ${ }^{+}$

No

Yes

Gestational age, wk

$32-33$
$34-36$
37
$38-40$
$\geq 41$

Oxygen exposure and BPD ${ }^{\dagger}$

No oxygen exposure, reference no BPD

$\begin{array}{lllll}<200 \text { hours oxygen, no BPD } & 0.28 & 1.32 & 1.12-1.57 & 0.0012 \\ \geq 200 \text { hours oxygen, no BPD } & 0.69 & 2.00 & 1.37-2.90 & 0.0003 \\ \text { BPD } & 1.03 & 2.80 & 1.31-5.98 & 0.0078\end{array}$

Unspecified respiratory hospitalization $^{\dagger}$

None

reference
Table 2 Risk factors for recurrent wheezing in the fifth year of life using logistic regression* (Continued)

\begin{tabular}{lcccc}
\hline $\begin{array}{l}\text { Uncomplicated } \\
\text { hospitalization }\end{array}$ & 0.50 & 1.65 & $0.98-2.79$ & 0.0594 \\
$\begin{array}{l}\text { Prolonged hospitalization } \\
\text { Laboratory-confirmed, }\end{array}$ & 1.24 & 3.46 & $1.94-6.16$ & $<.0001$ \\
$\begin{array}{l}\text { medically attended } \\
\text { RSV infection }\end{array}$ & & & & \\
\end{tabular}

$\begin{array}{lcccc}\text { None } & \text { reference } & & & \\ \text { Outpatient visit only } & 0.32 & 1.38 & 1.03-1.85 & 0.0307 \\ \begin{array}{l}\text { Uncomplicated } \\ \text { hospitalization }\end{array} & 0.68 & 1.98 & 1.39-2.81 & 0.0002 \\ \begin{array}{l}\text { Prolonged hospitalization } \\ \text { Prolong }\end{array} & 0.95 & 2.59 & 1.49-4.50 & 0.0007\end{array}$

Laboratory-confirmed, medically attended infection with other pathogen ${ }^{\dagger}$

\begin{tabular}{lcccc} 
None & reference & & & \\
Outpatient visit only & 0.26 & 1.30 & $0.62-0.69$ & 0.4883 \\
$\begin{array}{l}\text { Uncomplicated } \\
\text { hospitalization }\end{array}$ & 0.32 & 1.38 & $0.54-3.52$ & 0.4981 \\
Prolonged hospitalization & 0.74 & 2.10 & $0.76-5.80$ & 0.1526 \\
\hline
\end{tabular}

Abbreviations: BPD Bronchopulmonary dysplasia, Cl Confidence interval, RSV Respiratory syncytial virus, wk week, y year.

*Based on study cohort of 72,602 children, of whom 3380 had recurrent wheezing in the fifth year of life. See text for description of cohort and definition of recurrent wheezing. Results have been adjusting for infant and mother demographic and clinical characteristics.

${ }^{\dagger}$ Please refer to the appropriate section of the footnotes to Table 2 for further details.

${ }^{\ddagger}$ Percent adherence to recommended course per AAP guidelines, see online appendix for details of how adherence was calculated.

Additional file 1 Table S2 analyses using this definition are available upon request by interested readers.

\section{Recurrent wheezing in preterm and term infants}

We quantified the occurrence of any RW episode (outpatient or inpatient encounter with ICD diagnosis 493.xx) across all study years in term and premature infants. This approach demonstrated higher rates of RW encounters among infants with RSV infection compared with infants without RSV infection and also a gradient by severity of RSV infection. Approximately 30\%-60\% of premature infants 32-36 weeks GA with RSV infection during the first year of life will have a recurrent wheezing episode by age 5 years and $40 \%$ will have $>1$ episode. The overall rate of inpatient encounters with a wheezing diagnosis among premature infants without RSV infections in infancy was 56 per 1,000 children by age 5 years, whereas the rate among those that did have RSV infection was 102 per 1,000 children; the corresponding rates for term infants were 27 and 111, respectively. With respect to outpatient encounters, the respective rates were 1,097 and 2,352 per 1,000 children for premature infants and 743 and 2,152 for term infants. 
Table 3 Recurrent wheezing during study period

\begin{tabular}{|c|c|c|c|c|c|c|c|c|c|c|c|}
\hline & \multirow[b]{2}{*}{$\mathbf{N}$} & \multicolumn{2}{|c|}{ RW 2nd Year } & \multicolumn{2}{|c|}{ RW 3rd Year } & \multicolumn{2}{|c|}{ RW 4th Year } & \multicolumn{2}{|c|}{ RW 5th Year } & \multicolumn{2}{|c|}{ RW 2nd-5th Years } \\
\hline & & $\mathrm{n}$ & $\%$ & $\mathrm{n}$ & $\%$ & $\mathrm{n}$ & $\%$ & $n$ & $\%$ & n & $\%$ \\
\hline All children & 72,602 & 4,091 & 5.6 & 3,492 & 4.8 & 3,466 & 4.8 & 3,380 & 4.7 & 9,151 & 12.6 \\
\hline \multicolumn{12}{|l|}{ Sex } \\
\hline Female & 35,606 & 1,402 & 3.9 & 1,261 & 3.5 & 1,318 & 3.7 & 1,330 & 3.7 & 3,499 & 9.8 \\
\hline Male & 36,996 & 2,689 & 7.3 & 2,231 & 6.0 & 2,148 & 5.8 & 2,050 & 5.5 & 5,652 & 15.3 \\
\hline \multicolumn{12}{|l|}{ Race ${ }^{*}$} \\
\hline White & 31,580 & 1,650 & 5.2 & 1,443 & 4.6 & 1,353 & 4.3 & 1,265 & 4.0 & 3,642 & 11.5 \\
\hline African-American & 6,454 & 517 & 8.0 & 409 & 6.3 & 420 & 6.5 & 441 & 6.8 & 1,093 & 16.9 \\
\hline Asian & 14,476 & 807 & 5.6 & 774 & 5.3 & 785 & 5.4 & 764 & 5.3 & 1,983 & 13.7 \\
\hline Hispanic & 15,189 & 876 & 5.8 & 644 & 4.2 & 670 & 4.4 & 664 & 4.4 & 1841 & 12.1 \\
\hline Other/unknown & 4,903 & 241 & 4.9 & 222 & 4.5 & 238 & 4.9 & 246 & 5.0 & 592 & 12.1 \\
\hline \multicolumn{12}{|l|}{ Maternal age, y } \\
\hline$<18$ & 911 & 55 & 6.0 & 38 & 4.2 & 37 & 4.1 & 44 & 4.8 & 118 & 13.0 \\
\hline $18-34$ & 53,125 & 3,068 & 5.8 & 2,530 & 4.8 & 2,571 & 4.8 & 2,453 & 4.6 & 6,779 & 12.8 \\
\hline$\geq 35$ & 18,566 & 968 & 5.2 & 924 & 5.0 & 858 & 4.6 & 883 & 4.8 & 2,254 & 12.1 \\
\hline \multicolumn{12}{|l|}{ Family history of asthma* } \\
\hline None & 68,824 & 3,698 & 5.4 & 3,131 & 4.5 & 3,135 & 4.6 & 3,053 & 4.4 & 8,320 & 12.1 \\
\hline Father only & 1,087 & 91 & 8.4 & 94 & 8.6 & 92 & 8.5 & 83 & 7.6 & 220 & 20.2 \\
\hline Mother only & 2,633 & 294 & 11.2 & 258 & 9.8 & 232 & 8.8 & 240 & 9.1 & 596 & 22.6 \\
\hline Both parents & 58 & 8 & 13.8 & 9 & 15.5 & 7 & 12.1 & 4 & 6.9 & 15 & 25.9 \\
\hline \multicolumn{12}{|l|}{ Sibling aged $<5 \mathrm{y}$ in home } \\
\hline None & 44,590 & 2,358 & 5.3 & 2,127 & 4.8 & 2,246 & 5.0 & 2,197 & 4.9 & 5,631 & 12.6 \\
\hline$\geq 1$ & 28,012 & 1,733 & 6.2 & 1,365 & 4.9 & 1,220 & 4.4 & 1,183 & 4.2 & 3,520 & 12.6 \\
\hline \multicolumn{12}{|l|}{ Congenital anomaly* } \\
\hline Absent & 67,605 & 3,739 & 5.5 & 3,176 & 4.7 & 3,170 & 4.7 & 3,079 & 4.6 & 8,371 & 12.4 \\
\hline Present & 4,997 & 352 & 7.0 & 316 & 6.3 & 296 & 5.9 & 301 & 6.0 & 780 & 15.6 \\
\hline \multicolumn{12}{|l|}{ Small for gestational age ${ }^{*}$} \\
\hline No & 71,582 & 4,011 & 5.6 & 3,424 & 4.8 & 3,405 & 4.8 & 3,328 & 4.6 & 8,989 & 12.6 \\
\hline Yes & 1020 & 80 & 7.8 & 68 & 6.7 & 61 & 6.0 & 52 & 5.1 & 162 & 15.9 \\
\hline \multicolumn{12}{|l|}{ Gestational age, wk* } \\
\hline $32-33$ & 936 & 99 & 10.6 & 81 & 8.7 & 78 & 8.3 & 75 & 8.0 & 188 & 20.1 \\
\hline $34-36$ & 4,665 & 401 & 8.6 & 290 & 6.2 & 294 & 6.3 & 294 & 6.3 & 793 & 17.0 \\
\hline 37 & 4,582 & 270 & 5.9 & 264 & 5.8 & 209 & 4.6 & 238 & 5.2 & 635 & 13.9 \\
\hline $38-40$ & 51,049 & 2,763 & 5.4 & 2,373 & 4.6 & 2,345 & 4.6 & 2,290 & 4.5 & 6,235 & 12.2 \\
\hline$\geq 41$ & 11,370 & 558 & 4.9 & 484 & 4.3 & 540 & 4.7 & 483 & 4.2 & 1,300 & 11.4 \\
\hline \multicolumn{12}{|l|}{ Oxygen exposure* and BPD* } \\
\hline No oxygen, no BPD & 6,9821 & 3,819 & 5.5 & 3,267 & 4.7 & 3,249 & 4.7 & 3,162 & 4.5 & 8,607 & 12.3 \\
\hline$<200$ h Oxygen, no BPD & 2,431 & 221 & 9.1 & 177 & 7.3 & 165 & 6.8 & 173 & 7.1 & 445 & 18.3 \\
\hline$\geq 200$ h Oxygen, no BPD & 300 & 43 & 14.3 & 34 & 11.3 & 45 & 15.0 & 36 & 12.0 & 80 & 26.7 \\
\hline BPD & 50 & 8 & 16.0 & 14 & 28.0 & 7 & 14.0 & 9 & 18.0 & 19 & 38.0 \\
\hline \multicolumn{12}{|c|}{ Unspecified respiratory hospitalization* } \\
\hline None & 72,345 & 4017 & 5.6 & 3,449 & 4.8 & 3,420 & 4.7 & 3,348 & 4.6 & 9,052 & 12.5 \\
\hline Uncomplicated hospitalization & 177 & 47 & 26.6 & 24 & 13.6 & 26 & 14.7 & 16 & 9.0 & 64 & 36.2 \\
\hline Prolonged hospitalization & 80 & 27 & 33.8 & 19 & 23.8 & 20 & 25.0 & 16 & 20.0 & 35 & 43.8 \\
\hline
\end{tabular}


Table 3 Recurrent wheezing during study period (Continued)

\begin{tabular}{|c|c|c|c|c|c|c|c|c|c|c|c|}
\hline \multicolumn{12}{|c|}{$\begin{array}{l}\text { Laboratory-confirmed, medically attended } \\
\text { RSV infection* }\end{array}$} \\
\hline None & 71,336 & 3,829 & 5.4 & 3,326 & 4.7 & 3,312 & 4.6 & 3,280 & 4.6 & 8,748 & 12.3 \\
\hline Outpatient & 762 & 127 & 16.7 & 79 & 10.4 & 74 & 9.7 & 50 & 6.6 & 201 & 26.4 \\
\hline Uncomplicated hospitalization & 384 & 105 & 27.3 & 67 & 17.4 & 57 & 14.8 & 35 & 9.1 & 154 & 40.1 \\
\hline Prolonged hospitalization & 120 & 30 & 25.0 & 20 & 16.7 & 23 & 19.2 & 15 & 12.5 & 48 & 40.0 \\
\hline \multicolumn{12}{|c|}{$\begin{array}{l}\text { Laboratory-confirmed, medically attended } \\
\text { infection with other pathogen* }\end{array}$} \\
\hline None & 72,382 & 4,056 & 5.6 & 3,476 & 4.8 & 3,449 & 4.8 & 3,362 & 4.6 & 9,101 & 12.6 \\
\hline Outpatient & 119 & 20 & 16.8 & 7 & 5.9 & 7 & 5.9 & 8 & 6.7 & 30 & 25.2 \\
\hline Uncomplicated hospitalization & 64 & 7 & 10.9 & 3 & 4.7 & 5 & 7.8 & 5 & 7.8 & 10 & 15.6 \\
\hline Prolonged hospitalization & 37 & 8 & 21.6 & 6 & 16.2 & 5 & 13.5 & 5 & 13.5 & 10 & 27.0 \\
\hline \multicolumn{12}{|c|}{$\begin{array}{l}\text { Definite, medically attended RSV encounter } \\
\text { in the first year of life* }\end{array}$} \\
\hline No & 71,336 & 3,829 & 5.4 & 3,326 & 4.7 & 3,312 & 4.6 & 3,280 & 4.6 & 8,748 & 12.3 \\
\hline Yes & 1,266 & 262 & 20.7 & 166 & 13.1 & 154 & 12.2 & 100 & 7.9 & 403 & 31.8 \\
\hline
\end{tabular}

Abbreviations: BPD Bronchopulmonary dysplasia, RSV Respiratory syncytial virus, RW Recurrent wheezing, wk weeks, y years.

*Please refer to the appropriate section of the footnotes to Table 1 for further details.

\section{Discussion}

In this retrospective cohort study of children born at $\geq 32$ weeks GA, we found that three important risk factors (RSV disease in the first year of life, moderate prematurity, and exposure to supplemental oxygen in the neonatal period) had statistically significant associations with the development of RW5. This is consistent with our previous report, [14] where these predictors were associated with RW in the third year of life. Our study is concordant with and expands upon the study by Carroll et al. [13]. As was the case with that study, ours is a very large cohort, but ours had the advantage of including children born at $<37$ weeks gestation as well as actually documenting RSV infection, rather than just using the presence of a bronchiolitis diagnosis. Our study also found that other pathogens did not show a strong association. We also found that, consistent with the known epidemiology of asthma and RW, prevalence decreases over time, but among infants with certain risk factors including RSV infection, the prevalence of RW remained high in the fifth year. We found that these relationships persisted when we employed a more lenient definition of RW (accepting any instance of an asthma diagnosis). Future studies may be needed to better characterize the burden

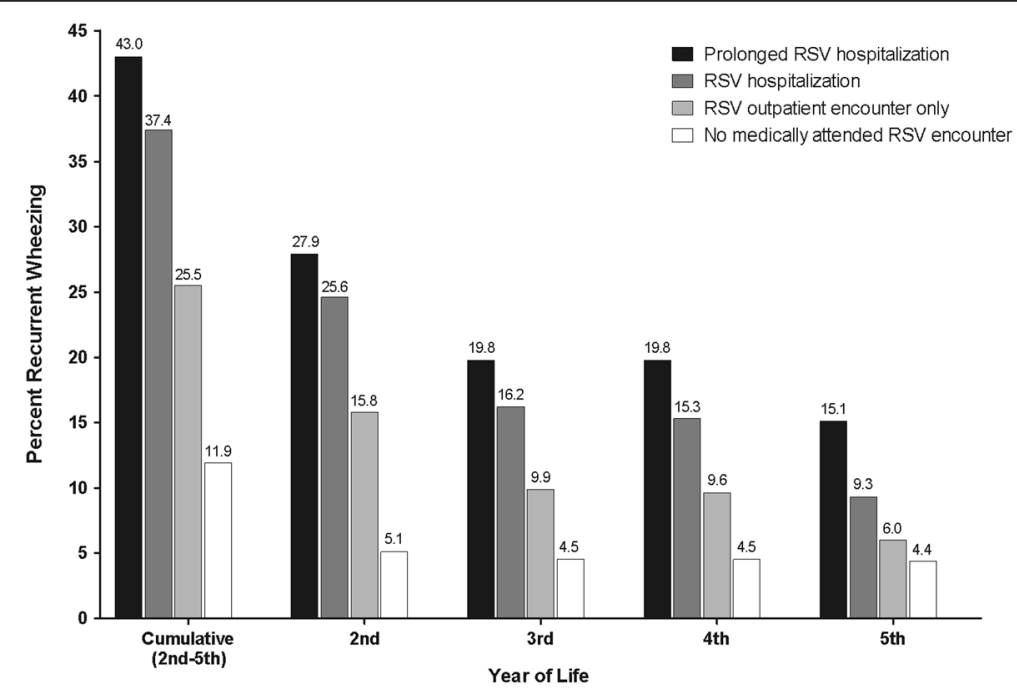

Figure 1 Relationship between respiratory syncytial virus infection encounters in year 1 with prevalence of recurrent wheezing in years 2 through $\mathbf{5}$ of life. Encounter types are hierarchical (prolonged hospitalization supersedes hospitalization, which supersedes outpatient encounter only) and mutually exclusive. RSV=respiratory syncytial virus. 
of these infants on the healthcare system and determine whether other strategies for mitigating the effects of RSV are possible. It is important to stress that our study is not in concordance with another very large study conducted in Finland, where Dunder et al. did not find an association between RSV epidemics and subsequent use of asthma medication [26]. The study by Dunder et al. is important because, like us, electronic scanning of asthma medications was employed for ascertainment.

In our previous report [14], we pointed out a number of limitations to our findings, of which the most important was that not all infants in our cohort were tested for RSV. Nonetheless, the presence of a severity gradient, the fact that the RSV effect observed in the third year of life persists into the fifth year, and the fact that other pathogens do not show this association, strongly support the notion that RSV infection in infancy is associated with asthma in childhood. This notion has been suggested by others [5-9]. However, it is important to note that some of our findings could be interpreted differently. For example, while it is true that our analyses clearly show a specific effect of documented RSV infection, it is striking that the relative contribution of this variable to the overall predictive ability of our model is small $(6.6 \%)$, while the contribution of non-modifiable risk factors such as sex, race, and family history was far greater. In this context, we must note that our lack of data on tobacco exposure is a significant limitation.

The presence of an association, however strong, does not constitute evidence of causality, and it is important to consider a number of possible causal paths, which are not mutually exclusive, that could explain our findings. The relationship of lower respiratory tract RSV disease to asthma is under investigation, particularly the role of genetic susceptibility for eventual asthma and the interaction of genetic susceptibility with the environment [27-29]. It remains unclear whether RSV infection disrupts neural control of bronchiolar smooth muscle setting the stage for sensitized airways or whether RSV disease serves as an additional insult to a host with pre-existing genetic susceptibility for eventual asthma [27,30-33]. One possibility is that infection with RSV causes lung damage that ultimately leads to the development of asthma. Such damage could be accentuated by oxygen exposure, prematurity, bronchopulmonary dysplasia, and/or environmental exposures (e.g., air pollution, secondhand smoke). Another possibility is that a set of genes exists that is preferentially expressed following infection with RSV. Such genes, which could also be affected by environmental factors, could lead to the occurrence of wheezing and asthma. It is also possible that a set of genes that are not identical to, but are related to, the development of asthma also code for a more exaggerated response to RSV infection, thus explaining the severity gradient noted by us and others.
Lastly, one cannot exclude the possibility that a subset of the population requires a severe RSV infection in order to develop asthma.

Given conflicting findings in the literature, with different studies and study types (e.g., twin studies) coming to different conclusions [28,34,35], a definitive explanation of the relationship of RSV infection to the development of asthma remains elusive [36]. What is clear is that future studies need to include more detail with respect to direct capture of genetic information. It is instructive to outline the components of what could be considered an optimal prospective study to explore the relationship between RSV infection in infancy and the development of asthma. Ideally, infants should be enrolled immediately after birth, and the initial intake process should include non-invasive collection of infant and parental DNA and a detailed history that includes special attention to family smoking history, history of atopy in parents and grandparents, and other possible environmental and allergen exposures (e.g., pets in the home). Subsequent follow-up should include frequent testing for respiratory pathogens [37], careful attention to the development of atopy, and an objective assessment of whether or not a child develops wheezing. The setting for such a study should be in an ethnically diverse population with a relatively high baseline prevalence of asthma.

\section{Conclusions}

We have found that predictors for recurrent wheezing in the third year of life also predict for recurrent wheezing in the fifth year. Of these, the most important potentially modifiable predictor was documented laboratory-confirmed, medically attended RSV infection in the first year of life. Future research in this area will need to incorporate genetic data collection, since purely observational studies do not permit definitive inferences as to causal pathways responsible for the association between RSV infection and subsequent wheezing.

\section{Additional file}

Additional file 1: Supplementary information.

\section{Abbreviations}

KPNC: Kaiser Permanente Northern California; RW: Recurrent wheezing; RW3: Recurrent wheezing at age 3 years; RW5: Recurrent wheezing at age 5 years; RSV: Respiratory syncytial virus.

\section{Competing interests}

At the time of this study, Dr. Masaquel was a Medlmmune employee and received an incentive plan. The other authors have no conflict of interest.

\section{Authors' contributions}

GJE was the principal investigator, had full access to all data in the study and supervised data collection, data cleaning, and, in conjunction with PK, the project statistician, supervised all project analyses. ASM was involved with the design of the study, interpretation of the data, and review of the manuscript. All authors agreed on the final text and conclusions of the manuscript. 


\section{Acknowledgments}

The manuscript was reviewed by Dr. Alan S. Go, Acting Director of the Kaiser Permanente Division of Research and Dr. Parthiv J. Mahadevia, Senior Director, Health Outcomes and Pharmacoeconomics, Medlmmune, LLC. We wish to thank Arona Ragins for her work in the early phases of this study, and Alina Schnake-Mahl and Complete Healthcare Communications, Inc. (Chadds Ford, PA) for formatting the manuscript.

\section{Author details}

${ }^{1}$ Division of Research, Perinatal Research Unit, Kaiser Permanente Medical Care Program, Oakland, CA, USA. ${ }^{2}$ Health Outcomes and

Pharmacoeconomics, Medlmmune, LLC, Gaithersburg, MD, USA.

${ }^{3}$ Management Information and Analysis, Kaiser Foundation Health Plan, Inc, Oakland, CA, USA.

Received: 30 January 2013 Accepted: 13 June 2013

Published: 19 June 2013

\section{References}

1. Glezen WP, Taber LH, Frank AL, Kasel JA: Risk of primary infection and reinfection with respiratory syncytial virus. Am J Dis Child 1986, 140(6):543-546.

2. Shay DK, Holman RC, Newman RD, Liu LL, Stout JW, Anderson LJ: Bronchiolitis-associated hospitalizations among US children, 1980-1996. JAMA 1999, 282(15):1440-1446.

3. Sampalis JS: Morbidity and mortality after RSV-associated hospitalizations among premature Canadian infants. J Pediatr 2003, 143(5 Suppl):S150-156.

4. Broughton S, Roberts A, Fox G, Pollina E, Zuckerman M, Chaudhry S, Greenough A: Prospective study of healthcare utilisation and respiratory morbidity due to RSV infection in prematurely born infants. Thorax 2005, 60(12):1039-1044.

5. Sigurs N, Bjarnason R, Sigurbergsson F, Kjellman B, Bjorksten B: Asthma and immunoglobulin $E$ antibodies after respiratory syncytial virus bronchiolitis: a prospective cohort study with matched controls. Pediatrics 1995, 95(4):500-505

6. Stein RT, Sherrill D, Morgan WJ, Holberg CJ, Halonen M, Taussig LM, Wright $\mathrm{AL}$, Martinez FD: Respiratory syncytial virus in early life and risk of wheeze and allergy by age 13 years. Lancet 1999, 354(9178):541-545.

7. Bont $L$, Aalderen WM, Kimpen JL: Long-term consequences of respiratory syncytial virus (RSV) bronchiolitis. Paediatr Respir Rev 2000, 1(3):221-227.

8. Martinez FD: Respiratory syncytial virus bronchiolitis and the pathogenesis of childhood asthma. Pediatr Infect Dis J 2003, 22(2 Suppl):S76-82.

9. Sigurs N, Gustafsson PM, Bjarnason R, Lundberg F, Schmidt S, Sigurbergsson F, Kjellman B: Severe respiratory syncytial virus bronchiolitis in infancy and asthma and allergy at age 13. Am J Respir Crit Care Med 2005, 171(2):137-141.

10. Henderson J, Hilliard TN, Sherriff A, Stalker D, Al Shammari N, Thomas HM: Hospitalization for RSV bronchiolitis before 12 months of age and subsequent asthma, atopy and wheeze: a longitudinal birth cohort study. Pediatr Allergy Immunol 2005, 16(5):386-392.

11. Carroll KN, Hartert TV: The impact of respiratory viral infection on wheezing illnesses and asthma exacerbations. Immunol Allergy Clin North Am 2008, 28(3):539-561. viii.

12. Mohapatra SS, Boyapalle S: Epidemiologic, experimental, and clinical links between respiratory syncytial virus infection and asthma. Clin Microbiol Rev 2008, 21(3):495-504.

13. Carroll KN, Wu P, Gebretsadik T, Griffin MR, Dupont WD, Mitchel EF, Hartert TV: The severity-dependent relationship of infant bronchiolitis on the risk and morbidity of early childhood asthma. J Allergy Clin Immunol 2009, 123(5):1055-1061. 1061 e1051.

14. Escobar GJ, Ragins A, Li S, Prager L, Masaquel AS, Kipnis P: Recurrent wheezing in the third year of life among children born at 32 weeks' gestation or later: relationship to laboratory-confirmed, medically attended infection with respiratory syncytial virus during the first year of life. Arch Pediatr Adolesc Med 2010, 164(10):915-922.

15. Korppi M, Kuikka L, Reijonen T, Remes K, Juntunen-Backman K, Launiala K: Bronchial asthma and hyperreactivity after early childhood bronchiolitis or pneumonia. An 8-year follow-up study. Arch Pediatr Adolesc Med 1994, 148(10):1079-1084.

16. Korppi M, Piippo-Savolainen E, Korhonen K, Remes S: Respiratory morbidity 20 years after RSV infection in infancy. Pediatr Pulmonol 2004, 38(2):155-160.
17. Martinez FD, Wright AL, Taussig LM, Holberg CJ, Halonen M, Morgan WJ: Asthma and wheezing in the first six years of life. The Group Health Medical Associates. N Engl J Med 1995, 332(3):133-138.

18. PMIC: ICD-9-CM (International Classification of Diseases, 9th Revision). In vol. 1, 2, and 3, Clinical Modification. 4th edition. PMIC (Practice Management Information Corporation; 2006.

19. Selby JV: Linking automated databases for research in managed care settings. Ann Intern Med 1997, 127 (8 Pt 2):719-724.

20. Joffe S, Escobar G, Black S, Armstrong M, Lieu T: Rehospitalization for respiratory syncytial virus among premature infants. Pediatrics 1999, 104(4 Pt 1):894-899.

21. Go AS, Hylek EM, Chang Y, Phillips KA, Henault LE, Capra AM, Jensvold NG, Selby JV, Singer DE: Anticoagulation therapy for stroke prevention in atrial fibrillation: how well do randomized trials translate into clinical practice? JAMA 2003, 290(20):2685-2692.

22. Escobar G, Clark R, Greene J: Short-term outcomes of infants born at 35 and 36 weeks gestation: we need to ask more questions. Semin Perinatol 2006, 30(1):28-33.

23. Escobar G, Gardner M, Chellino M, Fireman B, Verdi J, Yanover M: Identification of neonatal deaths in a large managed care organization. Paediatr Perinat Epidemiol 1997, 11(1):93-104.

24. Harrell F: Regression Modeling Strategies with Applications to Linear Models, Logistic Regression, and Survival Analysis. New York: Springer Verlag; 2001.

25. Render ML, Kim HM, Welsh DE, Timmons S, Johnston J, Hui S, Connors AF Jr, Wagner D, Daley J, Hofer TP: Automated intensive care unit risk adjustment: results from a National Veterans Affairs study. Crit Care Med 2003, 31(6):1638-1646.

26. Dunder $T$, Juntti H, Renko M, Kokkonen J, Waris M, Uhari M: Consumption of asthma medication after RS-virus epidemic-a population based survey. Pediat All Immu 2007, 18(2):105-109.

27. Long CE, McBride JT, Hall CB: Sequelae of respiratory syncytial virus infections. A role for intervention studies. Am J Respir Crit Care Med 1995 151(5):1678-1680. discussion 1680-1671.

28. Stensballe LG, Simonsen JB, Thomsen SF, Larsen AM, Lysdal SH, Aaby P, Kyvik KO, Skytthe A, Backer V, Bisgaard H: The causal direction in the association between respiratory syncytial virus hospitalization and asthma. J Allergy Clin Immunol 2009, 123(1):131-137. e131.

29. Thomsen SF, van der Sluis S, Stensballe LG, Posthuma D, Skytthe A, Kyvik $K O$, Duffy DL, Backer $V$, Bisgaard $H$ : Exploring the association between severe respiratory syncytial virus infection and asthma: a registry-based twin study. Am J Respir Crit Care Med 2009, 179(12):1091-1097.

30. Gilliland FD, Li YF, Gong H Jr, Diaz-Sanchez D: Glutathione s-transferases M1 and P1 prevent aggravation of allergic responses by secondhand smoke. Am J Respir Crit Care Med 2006, 174(12):1335-1341.

31. Salam MT, Lin PC, Avol EL, Gauderman WJ, Gilliland FD: Microsomal epoxide hydrolase, glutathione S-transferase P1, traffic and childhood asthma. Thorax 2007, 62(12):1050-1057.

32. Lee YL, Lin YC, Lee YC, Wang JY, Hsiue TR, Guo YL: Glutathione S-transferase P1 gene polymorphism and air pollution as interactive risk factors for childhood asthma. Clin Exp Allergy 2004, 34(11):1707-1713.

33. Chalmers JD, Singanayagam A, Akram AR, Mandal P, Short PM, Choudhury G, Wood V, Hill AT: Severity assessment tools for predicting mortality in hospitalised patients with community-acquired pneumonia. Systematic review and meta-analysis. Thorax 2010, 65(10):878-883.

34. Poorisrisak P, Halkjaer LB, Thomsen SF, Stensballe LG, Kyvik KO, Skytthe A, Schioetz $\mathrm{PO}$, Bisgaard $\mathrm{H}$ : Causal direction between respiratory syncytial virus bronchiolitis and asthma studied in monozygotic twins. Chest 2010, 138(2):338-344.

35. Sigurs N, Aljassim F, Kjellman B, Robinson PD, Sigurbergsson F, Bjarnason R, Gustafsson PM: Asthma and allergy patterns over 18 years after severe RSV bronchiolitis in the first year of life. Thorax 2010, 65(12):1045-1052.

36. Stein RT, Martinez FD: Respiratory syncytial virus and asthma: still no final answer. Thorax 2010, 65(12):1033-1034.

37. Lee WM, Grindle K, Pappas T, Marshall DJ, Moser MJ, Beaty EL, Shult PA, Prudent JR, Gern JE: High-throughput, sensitive, and accurate multiplex PCR-microsphere flow cytometry system for large-scale comprehensive detection of respiratory viruses. J Clin Microbiol 2007, 45(8):2626-2634.

doi:10.1186/1471-2431-13-97

Cite this article as: Escobar et al.: Persistent recurring wheezing in the fifth year of life after laboratory-confirmed, medically attended respiratory syncytial virus infection in infancy. BMC Pediatrics 2013 13:97. 